Original Research Article

\title{
A comparative study of functional outcome between platelet rich plasma injection versus steroid infiltration in plantar fasciitis
}

\author{
Harpreet Singh, Malay P. Gandhi*, Aliasgar J. Rampurwala, Tej S. Rudani
}

Department of Orthopaedics, Geetanjali Medical College and Hospital, Udaipur, Rajasthan, India

Received: 18 December 2019

Revised: 12 February 2020

Accepted: 14 February 2020

\section{*Correspondence:}

Dr. Malay P. Gandhi,

E-mail: malaygandhi98@yahoo.com

Copyright: (C) the author(s), publisher and licensee Medip Academy. This is an open-access article distributed under the terms of the Creative Commons Attribution Non-Commercial License, which permits unrestricted non-commercial use, distribution, and reproduction in any medium, provided the original work is properly cited.

\begin{abstract}
Background: Plantar fasciitis (PF) is considered as degenerative tendinopathies. Repeated micro trauma is the major etiology of these diseases. Autologous platelet rich plasma (PRP) injections are becoming more popular in the treatment of enthesopathies like PF. The growth factors in PRP cause tissue healing. We compared the result of injecting intra-lesional autologous PRP injections versus steroid infiltration in chronic PF.

Methods: A prospective, interventional and analytic comparative study was done and 81 patients (120 heels) were included in this study and were followed up for 6 months. We assessed the outcome of each patient using visual analog score (VAS) and foot and ankle disability index (FADI) on follow-up at 1, 3, and 6 months.

Results: In our study, female preponderance was seen. Left side was more common as compared to right side. Unilateral PF is more common than bilateral. The difference with in the individual group at baseline and at 1,3 and 6 months was statistically highly significant in terms of VAS and FADI ( $\mathrm{p}=0.0001)$ But the difference in the between the two groups was insignificant for VAS and FADI at 1,3 and 6 months.

Conclusions: In our study, as there is no significant difference in VAS and FADI score between corticosteroid injection group and PRP injection group at 1, 3 and 6 months follow up. So, it's reasonable to conclude that both are equally effective in PF. But as PRP injection comes out to be more time consuming and more costly, corticosteroid seems to be more efficient, cost and time wise. Hence, the latter should be a better choice.
\end{abstract}

Keywords: PRP, Corticosteroid, VAS, FADI

\section{INTRODUCTION}

Plantar fasciitis (PF) is a common pathological condition affecting the hindfoot, and can often be a challenge for physicians to successfully treat. ${ }^{1,2}$ It is an overuse injury causing inflammation at the origin of the plantar fascia and surrounding perifascial structures, such as the calcaneal periosteum. ${ }^{3-6}$ It is the most common clinical problem that causes inferomedial heel pain in adults. ${ }^{3-11}$
PF is usually seen as an overuse injury in athletes, runners in particular (accounting for nearly $10 \%$ of running injuries), but is also seen in the general population. ${ }^{12-19}$ Some of the factors frequently believed to precipitate $\mathrm{PF}$ include aberrant foot biomechanics and/or foot types, improper footwear, and obesity. ${ }^{14-20}$ More specifically, foot over-pronation is believed to put increased tension on the plantar soft tissues and create the potential for injury to occur. ${ }^{21}$ 
Despite the lack of understanding of the causes of PF, most authors agree that it is a self-limiting condition in the vast majority of cases and that surgery is not the treatment of choice. ${ }^{22}$ Approximately $95 \%$ of those with $\mathrm{PF}$ will have resolution of their symptoms in six to eighteen months. ${ }^{23}$

The mainstay of treatment for acute and chronic PF remains non- operative because conservative techniques are successful in over $90 \%$ of patients. ${ }^{24}$ However, there is no consensus about which treatments are the best or the most cost- effective, and there is inconsistency in the treatments provided by various practitioners. Nonsurgical management for the treatment of the symptoms and discomfort associated with plantar fasciitis can be classified into three broad categories: reducing pain and inflammation, reducing tissue stress to a tolerable level; and restoring muscle strength and flexibility of involved tissues. $^{25}$

Corticosteroid injections have been used to treat plantar heel pain since the 1950s. The advantages of corticosteroid injections include low cost, low complexity and rapid pain relief. However, many are concerned about the potential complications such as tendon rupture, associated with this treatment modality, which may offset its benefits. Thus, the recommendation of corticosteroid injections as an initial or tier 1 treatment option by the American College of Foot and Ankle Surgeons (ACFAS) has been met with much scepticism and raised certain controversial issues.

In an animal model the addition of growth factors to the ruptured tendon has been shown to increase the healing of the tendon. In humans it has been shown that the injection of whole blood into the tendon decreases the pain. Platelet rich plasma (PRP) is promoted as an ideal autologous biological blood-derived product, which can be exogenously applied to various tissues where it releases high concentrations of platelet derived growth factors that enhance wound healing, bone healing and also tendon healing. In addition, PRP possesses antimicrobial properties that may contribute to the prevention of infections. When platelets become activated, growth factors are released and initiate the body's natural healing response. ${ }^{26-29}$

The rationale for use of platelet-enriched preparations is to stimulate the natural healing cascade and tissue regeneration by a "supra-physiological" release of platelet derived growth factors directly at the site of treatment. Growth factors mediate the biological processes necessary for repair of soft tissues such as cartilage, muscle, tendon and ligament following acute traumatic, or overuse injury.

PRP is derived from the centrifugation of autologous whole blood and contains platelets concentration that is 3 to 5 times higher than that of normal whole blood. ${ }^{30,31} \mathrm{~A}$ relatively new strategy for the treatment of PF is the use of cell elements and bio-mediators of tissue response. In this context, the PRP has been configured as a perspective for improving clinical and structural outcomes by delivering a high concentration of growth factors that mediate healing. Its potential has been shown in vitro and in vivo studies; however, its real efficacy in $\mathrm{PF}$ is not well established. Thus, this study has the purpose to analyze the efficacy of PRP in management of $\mathrm{PF}$ as compared to that of steroid.

\section{Primary objective}

To compare short term and long-term difference in the outcome between PRP and steroid injection.

\section{Secondary objective}

To compare intragroup short and long-term outcome.

\section{METHODS}

A prospective, interventional and analytic comparative study was conducted in the Orthopaedics Department of Geetanjali Medical College and Hospital, in Udaipur, Rajasthan from January 2018 to June 2019. 120 patients diagnosed with PF and attending orthopaedics outpatient clinic were enrolled in this study.

\section{Inclusion criteria}

Patient diagnosed with plantar fasciitis, aged above 18 years of age and giving consent for study.

\section{Exclusion criteria}

Those patients who received local steroid/PRP injection within 6 months. Patient who had previous surgery at the site. Patient having nerve related symptoms, local infection, peripheral vascular disease, achilles tendon pathology, gout, rheumatoid arthritis and cogulopathy.

\section{Study procedure}

The study began after receiving Ethic Committee approval and by taking informed consent of the participants. They were randomly divided by alternate allocation into the two study groups (one who were to be injected with local corticosteroid and the second group to be locally injected with PRP). All the patients were enrolled by checking inclusion and exclusion criteria.

\section{Method of preparation of PRP}

Draw $10 \mathrm{ml}$ of venous blood using $10 \mathrm{ml}$ disposable syringe and pour in to one $8.5 \mathrm{ml}$ anticoagulant citrate dextrose solution formula A (ACD-A) containing vacuum sterile glass tube. The blood sample was then centrifuged for $1100 \mathrm{rpm}$ for $10 \mathrm{~min}$ at 22 degree Celsius in centrifuge machine (resulting in the three following layers: the inferior layer composed of erythrocytes, the 
intermediate layer composed of leukocytes, and the superior layer made of plasma). Using $10 \mathrm{cc}$ disposable syringe PRP was aspirated and used for the injection within 30 minutes of preparation. Remaining platelet poor plasma was discarded, as shown in (Figure 1).

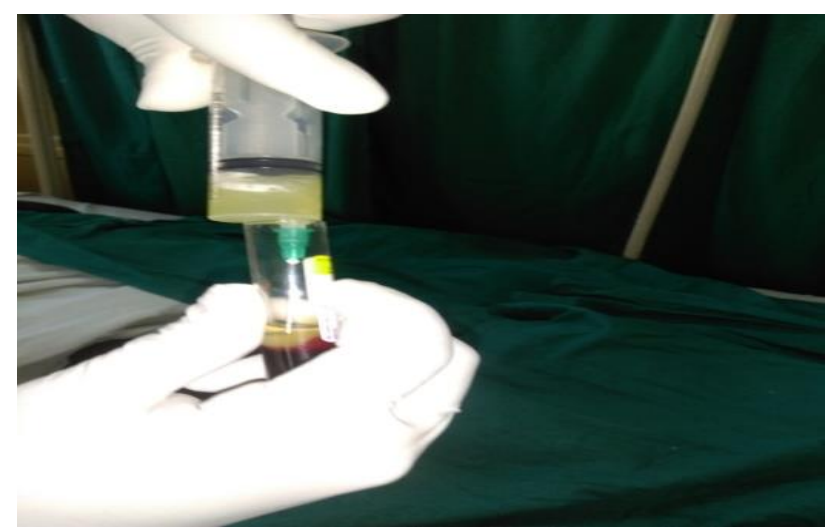

Figure 1: PRP aspirated in syringe after centrifuge.

An aliquot of product was sent to the laboratory for analysis of platelet concentration. All the procedures were performed in the same office setting. No activating agent (calcium chloride and thrombin) were used. Prepared amount of PRP was used for local injection into the patient according to below mentioned technique. By the above method we achieved average about 3 to 4 fold increase in platelet concentration over baseline platelet count.

\section{Technique}

\section{Prepare injection technique}

3-4 ml of PRP injection was given under full aseptic conditions. Patient was asked to sit on the procedure table with the lower limb in "figure of 4" position with foot resting on the table, so as to enable access to the medial border of heel. A needle of 18 gauze size was inserted at the maximal tenderness in plantar fascia i.e., medial aspect of the foot at the origin of plantar fascia usually is marked using a marker. Using a peppering technique. This technique involved a single skin portal and then multiple penetration of the fascia. The patient was then asked to dorsiflex and plantarflex the ankle to allow the PRP to spread throughout the plantar fascia. Post injection, patients are rested for $15 \mathrm{~min}$ and then allowed to walk. Patients are adviced to avoid strenous activities for 2 weeks. Patients were given acetaminophen for pain for 3 days.

\section{Corticosteroid injection technique}

Patient is similarly positioned and prepared like above. $1 \mathrm{ml}$ of lidocaine mixed with $1 \mathrm{ml}$ of depomedrol injection at the local site. Only single injection of Corticosteroid is given. Post injection measure are same as above.

\section{Assessment schedule}

Patients was undergone assessment with foot and ankle disability index (FADI) and visual analog score (VAS) at 0 day, 1 month, 3 month, and 6 months.

\section{Statistical analysis}

The data was entered into the Microsoft excel version 2016 and analyses was done using statistical package for social science version SPSS 25.0. Frequency of demographic variables, clinical variables, co-morbidities, functional outcomes in terms of FADI and VAS at 0 day, 1 month, 3 month, and 6 months was calculated. The difference between FADI and VAS at 0 day, 1 month, 3 month, and 6 months was calculated between the twogroup using unpaired $t$ test and in the same group using Paired t test. The difference in frequency of male-female was calculated using Fischer's exact test. P value less than 0.05 was considered as statistically significant.

\section{RESULTS}

In our study, we recruited a total of 81 patients, in whom there were 39 numbers of patients with bilateral involvement (in whom injection were given bilaterally) and there were 42 numbers of patients with unilateral involvement. Hence the total numbers of heels injected were 120. The PRP group was having 39 patients and Steroid group had 42 patients.

The mean age group in our study was 45.60 years with standard deviation of 9.28 years. Majority of the patients were from age group 41-50 years. In PRP group, the mean age was 44.25 and standard deviation was 10.62 years. In Steroid group, the mean age was 46.85 with standard deviation of 7.74 years. Both the groups were comparable in terms of age. The difference in mean age between the two groups was statistically insignificant. $(\mathrm{p}=0.2097)$ (Figure 2).

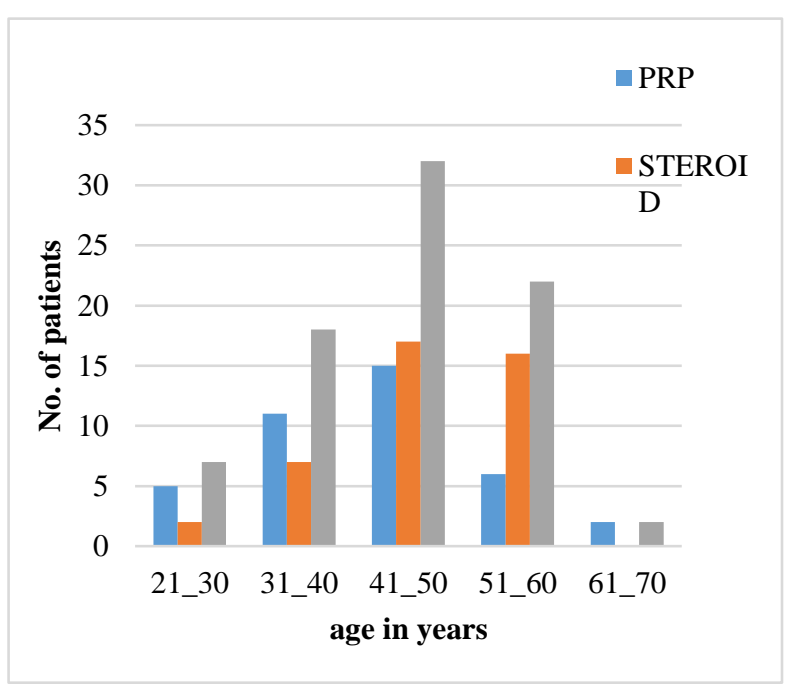

Figure 2: Age wise distribution. 
In our study, female preponderance was seen i.e., out of 81 patients recruited, 49 were females and rest were males (Figure 3). In our study, left side was more common as compared to right side (Figure 4). In our study, unilateral PF was more common than bilateral (Figure 5).

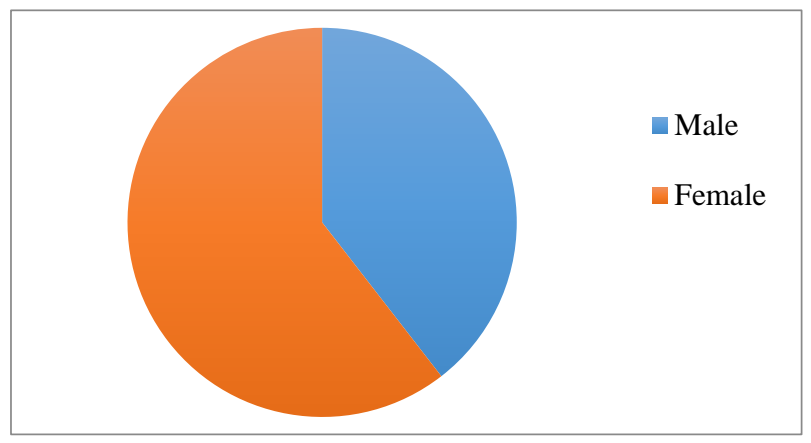

Figure 3: Gender wise distribution.

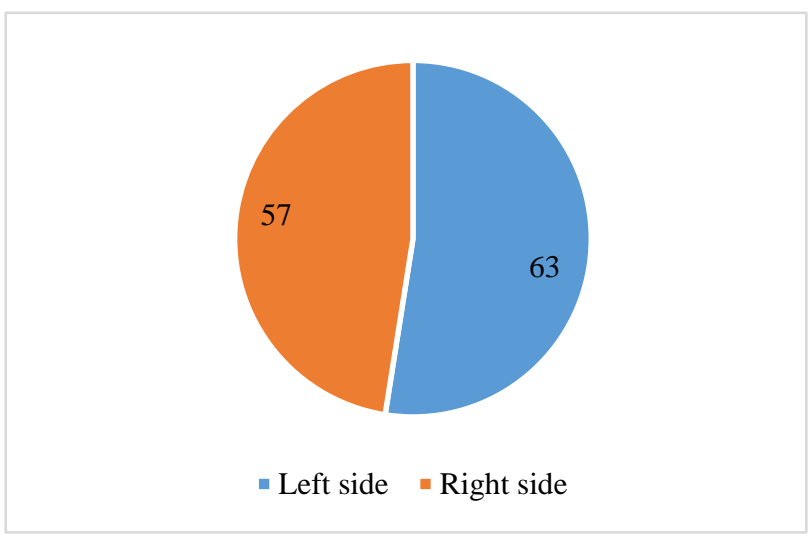

Figure 4: Left side was more common than right side in plantar fasciitis.

Within the same group, the difference of pain and FADI at baseline and at 1,3 , and 6 months was statistically highly significant. $(\mathrm{p}=0.0001)$, both in steroid group and in the PRP group. As shown in (Table 3). When the outcome between the two groups was compared, there was no statistically significant difference in VAS and FADI at any of the follow-up visits; as shown in (Table 4).

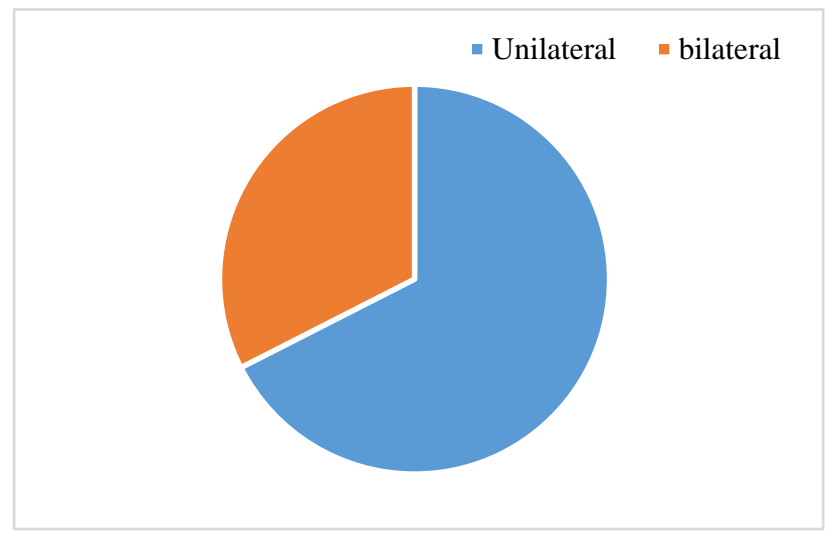

Figure 5: Unilateral common than bilateral.

Table 1: Intragroup reduction in pain outcome.

\begin{tabular}{|lll|}
\hline & VAS-PRP & VAS-steroid \\
\hline Baseline & 8.35 & 7.75 \\
\hline 1 month & 6.11 & 4.88 \\
\hline 3 months & 3.26 & 2.85 \\
\hline 6 months & .63 & 1.21 \\
\hline
\end{tabular}

Intragroup reduction in VAS.

Table 2: Intragroup reduction in FADI score.

\begin{tabular}{|l|l|l|}
\hline & FADI-PRP & FADI-steroid \\
\hline Baseline & 73.40 & 74.68 \\
\hline 1 month & 63.35 & 58.68 \\
\hline 3 months & 41.83 & 43.60 \\
\hline 6 months & 25.18 & 35.31 \\
\hline
\end{tabular}

Intragroup reduction in FADI score.

Table 3: Paired t test.

\begin{tabular}{|c|c|c|c|c|c|c|c|c|c|c|}
\hline & \multicolumn{5}{|c|}{ Paired differences } & \multirow{3}{*}{$\mathrm{T}$ test } & \multirow{3}{*}{ df } & \multirow{3}{*}{$\begin{array}{l}\text { Sig. } \\
(2- \\
\text { tailed) }\end{array}$} \\
\hline & & & \multirow[t]{2}{*}{ Mean } & \multirow[t]{2}{*}{ \pm SD } & \multirow{2}{*}{$\begin{array}{l}\text { Std. } \\
\text { error } \\
\text { mean }\end{array}$} & \multicolumn{2}{|c|}{$\begin{array}{l}95 \% \text { confidence interval } \\
\text { of the difference }\end{array}$} & & & \\
\hline & & & & & & Lower & Upper & & & \\
\hline \multirow{6}{*}{ PRP } & Pair 1 & $\begin{array}{l}\text { VAS } 0 \text { day- } \\
\text { VAS } 1 \text { month }\end{array}$ & 2.23 & \pm 0.92 & 0.11 & 1.99 & 2.47 & 18.65 & 59 & 0.000 \\
\hline & Pair 2 & $\begin{array}{l}\text { VAS } 0 \text { day- } \\
\text { VAS } 3 \text { month }\end{array}$ & 5.08 & \pm 1.16 & 0.15 & 4.78 & 5.38 & 33.69 & 59 & 0.000 \\
\hline & Pair 3 & $\begin{array}{l}\text { VAS } 0 \text { day- } \\
\text { VAS } 6 \text { month }\end{array}$ & 7.71 & \pm 1.30 & 0.16 & 7.38 & 8.05 & 45.87 & 59 & 0.000 \\
\hline & Pair 4 & $\begin{array}{l}\text { FADI } 0 \text { day- } \\
\text { FADI } 1 \text { month }\end{array}$ & 10.05 & \pm 0.81 & 0.10 & 9.84 & 10.25 & 95.93 & 59 & 0.000 \\
\hline & Pair 5 & $\begin{array}{l}\text { FADI } 0 \text { day- } \\
\text { FADI } 3 \text { month }\end{array}$ & 31.56 & \pm 3.19 & 0.41 & 30.74 & 32.39 & 76.50 & 59 & 0.000 \\
\hline & Pair 6 & $\begin{array}{l}\text { FADI } 0 \text { day- } \\
\text { FADI } 6 \text { month }\end{array}$ & 48.21 & \pm 3.21 & 0.41 & 47.38 & 49.04 & 116.13 & 59 & 0.000 \\
\hline
\end{tabular}

Continued. 


\begin{tabular}{|c|c|c|c|c|c|c|c|c|c|c|}
\hline & & & \multicolumn{5}{|c|}{ Paired differences } & \multirow{3}{*}{$\mathrm{T}$ test } & \multirow{3}{*}{ df } & \multirow{3}{*}{$\begin{array}{l}\text { Sig. } \\
(2- \\
\text { tailed) }\end{array}$} \\
\hline & & & \multirow[t]{2}{*}{ Mean } & \multirow[t]{2}{*}{$\pm \mathrm{SD}$} & \multirow{2}{*}{$\begin{array}{l}\text { Std. } \\
\text { error } \\
\text { mean }\end{array}$} & \multicolumn{2}{|c|}{$\begin{array}{l}95 \% \text { confidence interval } \\
\text { of the difference }\end{array}$} & & & \\
\hline & & & & & & Lower & Upper & & & \\
\hline \multirow{6}{*}{ Steroid } & Pair 1 & $\begin{array}{l}\text { VAS } 0 \text { day- } \\
\text { VAS } 1 \text { month }\end{array}$ & 2.86 & \pm 0.96 & 0.12 & 2.61 & 3.11 & 23.01 & 59 & 0.000 \\
\hline & Pair 2 & $\begin{array}{l}\text { VAS } 0 \text { day- } \\
\text { VAS } 3 \text { month }\end{array}$ & 4.90 & \pm 1.13 & 0.14 & 4.60 & 5.19 & 33.57 & 59 & 0.000 \\
\hline & Pair 3 & $\begin{array}{l}\text { VAS } 0 \text { day- } \\
\text { VAS } 6 \text { month }\end{array}$ & 6.53 & \pm 1.51 & 0.19 & 6.14 & 6.92 & 33.46 & 59 & 0.000 \\
\hline & Pair 4 & $\begin{array}{l}\text { FADI } 0 \text { day- } \\
\text { FADI } 1 \text { month }\end{array}$ & 16.00 & \pm 6.02 & 0.77 & 14.44 & 17.55 & 20.55 & 59 & 0.000 \\
\hline & Pair 5 & $\begin{array}{l}\text { FADI } 0 \text { day- } \\
\text { FADI } 3 \text { month }\end{array}$ & 31.08 & \pm 4.31 & 0.55 & 29.96 & 32.19 & 55.79 & 59 & 0.000 \\
\hline & Pair 6 & $\begin{array}{l}\text { FADI } 0 \text { day- } \\
\text { FADI } 6 \text { month }\end{array}$ & 39.36 & \pm 6.42 & 0.82 & 37.70 & 41.02 & 47.45 & 59 & 0.000 \\
\hline
\end{tabular}

Table 4: Unpaired t test.

\begin{tabular}{|c|c|c|c|c|c|c|c|}
\hline & \multicolumn{3}{|l|}{ PRP } & \multicolumn{3}{|c|}{ Steroid } & \multirow{2}{*}{ P value } \\
\hline & Mean & \pm SD & $\begin{array}{l}\text { Std. error } \\
\text { mean }\end{array}$ & Mean & SD & $\begin{array}{l}\text { Std. error } \\
\text { mean }\end{array}$ & \\
\hline Age & 44.25 & \pm 10.62 & 1.37 & 46.85 & 7.74 & 1.03 & 0.2097 \\
\hline VAS O day & 8.35 & \pm 0.84 & 0.1 & 7.75 & 0.91 & 0.11 & 0.564 \\
\hline VAS 1 month & 6.11 & \pm 1.22 & 0.15 & 4.88 & 1.19 & 0.15 & 0.849 \\
\hline VAS 3 month & 3.26 & \pm 1.26 & 0.16 & 2.85 & 1.23 & 0.15 & 0.631 \\
\hline VAS 6 month & 0.63 & \pm 1.2 & 0.15 & 1.21 & 1.49 & 0.19 & 0.07 \\
\hline FADI 0 day & 73.4 & \pm 14.2 & 1.83 & 74.68 & 13.37 & 1.72 & 0.684 \\
\hline FADI 1 month & 63.35 & \pm 14.31 & 1.84 & 58.68 & 12.57 & 1.62 & 0.248 \\
\hline FADI 3 month & 41.83 & \pm 13.35 & 1.72 & 43.6 & 11.82 & 1.52 & 0.387 \\
\hline FADI 6 month & 25.18 & \pm 12.66 & 1.63 & 35.31 & 11.57 & 1.49 & 0.633 \\
\hline
\end{tabular}

\section{DISCUSSION}

In recent years, the use of PRP has increased in diverse clinical situations such as biological and autologous therapeutic alternatives. We conducted the study with the objective to evaluate the difference in outcome between PRP Injection and Steroid Infiltration in PF.

In our study, there were total 81 patients and 120 heels were included. There were 49 female and 32 males; so female preponderance was seen.

The mean age group was 45.60 years, with standard deviation of 9.28 years. Majority of the patients were from age group 41-50 years. In PRP group, the mean age was 44.25 and standard deviation was 10.62 years. In Steroid group, the mean age was 46.85 with standard deviation of 7.74 years. The difference between the two groups was statistically insignificant $(p=0.2097)$; hence both the groups were comparable. The mean age was similar to another study done by Acosta-Olivo et al in 2017 who reported the average age of the patients was 44.8 years (range, 24-61 years).$^{32}$ Also another study of
PRP injection done by Ragab et al in 2012, on 25 patients with chronic plantar fasciitis, reported mean age of 44 years in their patients. ${ }^{33}$

In our study a total of 120 sites were affected and left side was more common. Unilateral involvement was more common than bilateral. In contrast, a study done by Acosta-Olivo et al 2017, reported that the right foot was more frequently affected foot $(63 \%){ }^{32}$

Before the procedure, the mean VAS at baseline was 8.05 with standard deviation of 0.95 irrespective of the group. Most of the patient had a VAS of either 8 or 9 . The mean VAS at baseline for PRP group was $8.35 \pm 0.84$; and for steroid group it was $7.75 \pm 0.91$. The difference between the VAS at baseline was statistically insignificant i.e. $\mathrm{p}=0.564$. So, the groups were comparable.

At one month, the mean VAS was $5.5 \pm 1.35$ irrespective of the group. The majority of the patients had a VAS of 6 . The mean VAS at 1 month for PRP was 6.11 1.22 , and for steroid it was $4.88 \pm 1.19$. The difference between the two groups was insignificant $(\mathrm{p}=0.849)$. 
At 3 months, the mean VAS was $3.05 \pm 1.25$ irrespective of the group. The mean VAS at 3 months for PRP was $3.26 \pm 1.26$, and for steroid it was $2.85 \pm 1.23$. The difference between the two groups was insignificant. $(\mathrm{p}=0.631)$.

At 6 months, the mean VAS was $0.92 \pm 1.38$ irrespective of the group. The mean VAS at 6 months for PRP was $0.633 \pm 1.2$, and for steroid it was $1.21 \pm 1.49$. The difference between the two groups was insignificant $(\mathrm{p}=0.070)$. During patient follow-up, an improvement in pain was found in both groups, but the difference was not statistically significant between the two groups.

In a study done by Martinelli et al in 2013, they concluded that VAS for pain was significantly decreased from $7.1 \pm 1.1$ before treatment to $1.9 \pm 1.5$ at the last follow-up ( $<<0.01)$ after PRP injection. ${ }^{34}$

In our study, the mean FADI score at baseline was $74.04 \pm 13.75$ irrespective of groups. The mean FADI score of PRP at baseline was $73.40 \pm 14.23$ and for steroid it was $74.68 \pm 13.37$; which was a statistically insignificant difference $(\mathrm{p}=0.684)$.

At 1 month, the mean FADI score was $61.01 \pm 13.62$ irrespective of groups. The mean FADI score of PRP at one month was $63.35 \pm 14.31$ and for steroid it was $58.68 \pm 12.57$; which was a statistically insignificant difference $(\mathrm{p}=0.248)$.

At 3 months, the mean FADI score was $42.71 \pm 12.59$ irrespective of groups. The mean FADI score of PRP at three months was $41.83 \pm 13.35$ and for steroid it was $43.60 \pm 11.82$; which was a statistically insignificant difference $(\mathrm{p}=0.387)$.

At 6 months, the mean FADI score was $30.25 \pm 13.10$. The mean FADI score of PRP at 6 months was $25.18 \pm 12.66$ and for steroid it was $35.31 \pm 11.57$. Thus, the difference between them was still statistically insignificant $(\mathrm{p}=0.248)$.

Acosta-Olivo et al in 2017 in their study showing comparison in between steroid and PRP injection reported that all scales used (VAS, FADI and AOFAS) showed that the difference was not statistically significant between the two groups. Moreover, they concluded that the use of PRP is an effective treatment method for patients with plantar fasciitis who do not respond to conservative treatment because PRP demonstrates an efficacy equal to that of steroids. ${ }^{32}$

In contrast to our results, a meta-analysis conducted by Yang et al 2007 concluded that PRP is superior to steroid treatments for long-term pain relief; however, significant differences were not observed between short and intermediate effects. ${ }^{35}$
In our series, no difference was seen in pain or functional result in between the two groups at any of the follow-up visits. PRP injection involves more invasive procedure than the corticosteroid, since the blood for PRP is also to be withdrawn from the patient. So, it effectively means piercing the needle twice for which patients are somehow reluctant. Whereas, for the Corticosteroid injection we have to prick the patient only once. PRP preparation is more time consuming as we have to take the blood from the patient and then the patient blood is sent to the laboratory for platelet analysis which takes around 10 to 15 minutes. After that, centrifuging it takes 30 to 40 minutes and platelet analysis in the laboratory takes another 10 to 15 minutes. That means that if we have to give PRP to the patient, then the patient has to wait up to one to one and half hour; where as to inject corticosteroid it will take only 15 to 20 minutes.

PRP injection proves to be costlier than the corticosteroid injection because it involves cost in getting CBC done, paying for PRP vial and getting the blood centrifuged in the laboratory.

In our study, as there is no significant difference in VAS and FADI score between corticosteroid injection and PRP injection at 1, 3 and 6 months follow up. So, they were determined to be equally effective in Plantar fasciitis. Since PRP injection was found to be more time consuming and more costly. Hence, corticosteroid seems to be a better option.

\section{CONCLUSION}

It seems reasonable to infer that corticosteroid injection may be a better choice given the same functional result in both the group.

Funding: No funding sources

Conflict of interest: None declared

Ethical approval: The study was approved by the institutional ethics committee

\section{REFERENCES}

1. Cornwall MW. Plantar fasciitis: etiology and treatment. Journal of Orthopaedic \& Sports Physical Therapy 1999;29:756-60.

2. Sammarco GJ, Helfrey RB. Surgical treatment of recalcitrant plantar fasciitis. Foot Ankle Int. 1996;17:520-6.

3. Kwong PK, Kay D, Voner RT, White MW. Plantar fasciitis. Mechanics and pathomechanics of treatment. Clin Sports Med. 1988;7:119-26.

4. Tisdel CL, Donley BG, Sferra JJ. Diagnosing and treating plantar fasciitis: a conservative approach to plantar heel pain. Cleveland Clin J Med. 1999;66:231-5.

5. Campbell-Giovaniello KJ. Clinical snapshot: plantar fasciitis. Am J Nurs. 1997;97:38-9. 
6. Bedi HS, Love BR. Differences in impulse distribution in patients with plantar fasciitis. Foot Ankle Int. 1998;19:153-6.

7. Young CC, Rutherford DS. Treatment of plantar fasciitis. Am Fam Phys. 2001;63:467-8.

8. Davies MS, Weiss GA. Plantar fasciitis: how successful is surgical intervention. Foot Ankle Int. 1999;20:803-7.

9. Acevedo JI, Beskin JL. Complications of plantar fascia rupture associated with corticosteroid injection. Foot Ankle Int. 1998;19:91-7.

10. Gill LH, Kiebzak GM. Outcome of nonsurgical treatment for plantar fasciitis. Foot Ankle Int. 1996;17:527-32.

11. Lapidus PW, Guidotti FP. Painful heel: report of 323 patients with 364 painful heels. Clin Orthop Rel Res. 1965;39:178-86.

12. Dimou ES, Brantingham JW Wood T. A randomized controlled trial (with blinded observer) of chiropractic manipulation and Achilles stretching vs. orthotics for the treatment of plantar fasciitis. J Am Chiro Assoc. 2004;41(9):32-42.

13. Di Giovanni BF, Nawoczenski DA, Lintal ME, Moore EA, Murray JC, Wilding GE, et al. Tissuespecific plantar fascia stretching exercise enhances outcomes in patients with chronic heel pain: a prospective, randomized study. J Bone Joint Surg. 2003;85A (7):1270-7.

14. Batt ME, Tanji JL. Plantar fasciitis: a prospective randomized clinical trial of the tension night splint. Clin J Sports Med. 1996;6(3):158-162.

15. Lynch DM, Goforth WP, Martin JE, Odom RD, Preece CK, Kotter MW. Conservative treatment of plantar fasciitis: a prospective study. J Am Pod Med Assoc. 1998;88(8):375-80.

16. Martin JE, Hosch JC, Goforth WP, Murff RT, Lynch DM, Odom RD. Mechanical treatment of plantar fasciitis: a prospective study. J Am Pod Med Assoc. 2001;91(2):55-62.

17. Buchbinder R. Plantar fasciitis. N Engl J Med. 2004;350(32):2159-66.

18. Crawford F, Thomson C. Interventions for treating plantar heel pain. The Cochrane Database of Systematic Reviews 2003;3:416.

19. Winemiller MH, Billow RG, Laskowski ER, Harmsen WS. Effect of magnetic vs sham-magnetic insoles on plantar heel pain: a randomized controlled trial. JAMA. 2003;290(11):1474-8.

20. Turlik MA, Donatelli TJ. A comparison of shoe inserts in relieving mechanical heel pain. Foot. 1999;9(2):84-7.

21. Crawford F, Snaith M. How effective is therapeutic ultrasound in the treatment of heel pain. Ann Rheum Dis. 1996;55:265-7.

22. Singh D, Angel J, Bentley G, Trevino SG. Fortnightly review. Plantar fasciitis. British Medical Journal 1997;315:172-5.

23. Kane DT, Greaney T, Shanahan M, Duffy G, Bresnihan B, Gibney $\mathrm{R}$, et al. The role of ultrasonography in the diagnosis and management of idiopathic plantar fasciitis. Rheumatology 2001;40:1002-8.

24. Ogden JA, Alvarez R, Levitt R, Cross GL, Marlow M. Shock wave therapy for chronic proximal plantar fasciitis. Clin Orthop Rel Res. 2001;387:47-59.

25. Pfeffer G, Bacchetti P, Deland J, Lewis A, Anderson R, Davis W, et al. Comparison of custom and prefabricated orthoses in the initial treatment of proximal plantar fasciitis. Foot \& Ankle International 1999;20:214-21.

26. Nirschl R. Elbow tendinosis/tennis elbow. Clin Sports Med. 1992;11:851-70.

27. Sclafani A, Romo T, Ukrainsky G, McCormick SA, Litner J, Kevy SV, et al. Modulation of wound response and soft tissue ingrowth in synthetic and allogeneic implants with platelet concentrate. Arch Facial Plast Surg. 2005;7:170-1.

28. Ranly D. Lohmann C, Andreacchio D, Boyan BD, Schwartz Z. Platelet-rich plasma inhibits demineralized bone matrix-induced bone formation in nude mice. J Bone Joint Surg [Am]. 2007;89:13947.

29. Edwards S, Calandruccio J. Autologous bloodinjections for refractory lateral epicondylitis. J Hand Surg Am. 2003;28:272-8.

30. Gobbi A, Karnatzikos G, Mahajan V, Malchira S. Platelet-rich plasma treatment in symptomatic patients with knee osteoarthritis preliminary results in a group of active patients. Sports Health. 2012;4(2):162-72.

31. Hamid AMS, Mohamed Ali MR, Yusof A, George J, Lee LP. Platelet-Rich Plasma Injections for the Treatment of Hamstring Injuries: A Randomized Controlled Trial. Am J Sports Med. 2014:2410-8.

32. Acosta-Olivo C, Elizondo-Rodriguez J, LopezCavazos R, Vilchez-Cavazos F, Simental-Mendia M, Mendoza-Lemus O. Plantar Fasciitis-A Comparison of Treatment with Intralesional Steroids versus Platelet-Rich Plasma A Randomized, Blinded Study. J Am Podiatr Med Assoc. 2017;107(6):490-6.

33. Ragab EM, Othman AM. Platelets rich plasma for treatment of chronic plantar fasciitis. Arch Orthop Trauma Surg. 2012;132(8):1065-70.

34. Martinelli N, Marinozzi A, Carnì S, Trovato U, Bianchi A, Denaro V. Platelet-rich plasma injections for chronic plantar fasciitis. Int Orthop. 2013;37(5):839-42.

35. Yang WY, Han YH, Cao XW, Pan JK, Zeng LF, Lin JT, et al. Platelet-rich plasma as a treatment for plantar fasciitis-A meta-analysis of randomized controlled trials. Medicine (Baltimore). 2017;96(44):8475.

Cite this article as: Singh $\mathrm{H}$, Gandhi MP, Rampurwala AJ, Rudani TS. A comparative study of functional outcome between platelet rich plasma injection versus steroid infiltration in plantar fasciitis. Int J Res Orthop 2020;6:393-9. 